\title{
Heart dysfunction in patients with acute ischemic stroke or TIA does not predict all-cause mortality at long-term follow-up
}

\author{
Alexandra Holmström ${ }^{1}$ Michael LX Fu', Clara Hjalmarsson², Lena Bokemark² and Björn Andersson ${ }^{2,3^{*}}$
}

\begin{abstract}
Background: Despite heart failure being a substantial risk factor for stroke, few studies have evaluated the predictive value of heart dysfunction for all-cause mortality in patients with acute ischemic stroke, in particular in the elderly. The aim of this study was to investigate whether impaired heart function in elderly patients can predict all-cause mortality after acute ischemic stroke or transient ischemic attack (TIA).
\end{abstract}

Methods: A prospective long-term follow-up analysis was performed on a hospital cohort consisting of $n=132$ patients with mean age $73 \pm 9$ years, presenting with acute ischemic stroke or transient ischemic attack, without atrial fibrillation. All patients were examined by echocardiography during the hospital stay. Data about all-cause mortality were collected at the end of the follow-up period. The mean follow-up period was $56 \pm 22$ months.

Results: In this cohort, $58 \%$ of patients with acute ischemic stroke or TIA had heart dysfunction. Survival analysis showed that heart dysfunction did not predict all-cause mortality in this cohort. Furthermore, in multivariate regression analysis age (HR 5.401, Cl 1.97-14.78, $\mathrm{p}<0.01$ ), smoking (HR 3.181, Cl 1.36-7.47, $\mathrm{p}<0.01$ ), myocardial infarction (HR 2.826, $\mathrm{Cl} 1.17-6.83, \mathrm{p}<0.05)$ were independent predictors of all-cause mortality.

Conclusion: In this population with acute ischemic stroke or TIA and without non-valvular atrial fibrillation, impaired heart function does not seem to be a significant predictor of all-cause mortality at long-term follow-up.

Keywords: Echocardiography, Heart failure, Mortality, Stroke, TIA

\section{Background}

Ischemic stroke and heart failure are major causes of morbidity and mortality [1]. Previous studies have suggested that heart failure is associated with increased risk of ischemic stroke [2-7]. Risk factors for heart dysfunction are also hypertension, coronary artery diseases and diabetes mellitus. In a study of 1247 patients diagnosed with heart failure, Alberts et al. found that the risk of ischemic stroke was strongly increased shortly after the diagnosis and returned to normal within 6 months [3]. On the other hand, Witt et al. reported that the risk of suffering an ischemic stroke increased within the first 30 days after heart failure diagnosis and remained elevated

\footnotetext{
*Correspondence: bjorn.andersson@vgregion.se

2Department of Internal Medicine, Institute of Medicine, Sahlgrenska Academy, University of Gothenburg, Gothenburg, Sweden

${ }^{3}$ Department of Internal Medicine, Sahlgrenska University Hospital/Sahlgrenska, Blå Stråket 5, 41345 Göteborg, Sweden

Full list of author information is available at the end of the article
}

during the 5-year follow-up period [6]. The somewhat different results of these two studies could be due to differences in heart failure populations. Even though atrial fibrillation is a well-recognized risk factor for both heart failure and ischemic stroke [8-11], it is still unclear if heart dysfunction per se, in the absence of atrial fibrillation, is associated with increased risk of ischemic stroke. Moreover, it remains unknown whether heart dysfunction per se may predict poor outcome in patients with acute ischemic stroke or transient ischemic attack (TIA).

Heart failure was associated with poor prognosis and dependency in ischemic stroke patients [12-15]. It is currently discussed whether there is an independent association between low left ventricular ejection fraction (LVEF) and mortality in patients with ischemic stroke. Such an association between LVEF and mortality has been reported in some studies but not in all $[13,16]$.

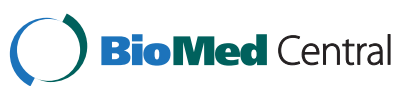


The purpose of this study was to investigate whether heart dysfunction, as defined by echocardiographic findings, in the absence of atrial fibrillation, may predict long-term all-cause mortality in elderly patients with acute ischemic stroke or TIA.

\section{Methods}

Study cohort

We performed a retrospective survival analysis of patients admitted to the Stroke Unit, at Department of Medicine, Sahlgrenska University Hospital, in Gothenburg, from February 9, 2005 through May 31, 2009. Due to problems related to data management, no patients were included from January 1, 2007 until September 6, 2007. Patients with ischemic stroke or TIA were included if an echocardiography was performed during hospital stay. Patients with a medical history of atrial fibrillation, or who were found to have atrial fibrillation on the 24 hours cardiac monitoring after admission were excluded.

Stroke was diagnosed according to the World Health Organization definition of stroke [17]. TIA was defined as a neurologic deficit that resolved completely within 24 hours. Within 24 hours of admission, a cerebral computertomography (CT) scan was performed on all patients. Treatment with antiplatelet drugs was initiated if the CT scan excluded cerebral bleeding. On admission, stroke severity was assessed by using National Institute of Health Stroke Scale (NIHSS) [18,19]; functional status was estimated by using Modified Rankin Scale (mRS) [20,21] at 3-month follow-up.

Heart function was measured by echocardiography. Heart dysfunction was either categorized as systolic dysfunction or diastolic dysfunction. Systolic dysfunction was defined as LVEF <50\% [22]. Diastolic dysfunction was defined as a combination of following criteria: 1) LVEF $\geq 50 \%$; 2) Normal-sized left ventricle [LVDD $\leq 5.5(\mathrm{~cm})]$; and 3 ) one of the following criteria: left ventricular hypertrophy; E/A ratio $<0.8$ or $\geq 1.5$; S/D ratio $<1$ or $>1$; left atrium $\geq 34\left(\mathrm{~cm}^{2}\right)$ [23]. Echocardiography was performed by an echocardiography specialist who was blinded to the other variables examined in the study and, moreover, was independent of study team. Inter-observers were LVEF estimation/ Simpson $22 / 27 \%$, diastolic/systolic volume $14 / 22 \%, 2 \mathrm{D}$ analyzing (mitral ring) 13\%, VTI LVOT 8\%. Doppler echocardiography was used to obtain transmitral flow and pulmonary venous flow determined from the apical four chamber view. To record transmitral flow, the sample volume was carefully positioned at the tip of the leaflets of mitral valve. The following variables were evaluated as parameters of left ventricular filling: peak of early diastolic (E) and late diastolic (A) flow velocity (E/A ratio), and peak pulmonary venous flow velocity during ventricular systole $(S)$, peak pulmonary venous flow velocity during ventricular diastole (D) (S/D ratio).
All images were stored in the hospital central image database for later review. The final diagnosis was validated by a cardiologist. The study was approved by the Ethics Committee at the University of Gothenburg. The study protocol conformed to the ethical guidelines of the 1975 Declaration of Helsinki.

\section{Laboratory analyses at baseline}

Serum-total cholesterol, hemoglobin, C-reactive protein (CRP), serum creatinine (S-creatinine), glomerular filtration rate (GFR), and cardiac troponin $\mathrm{T}$ (cTNT) were measured by routine laboratory methods within 24 hours of hospital admittance.

\section{Outcome data}

Information on all-cause mortality was collected from medical records and the Swedish populations register at the end of the follow-up period.

\section{Statistics}

The results are presented as percentage/mean \pm standard deviation (SD). Student's unpaired t-test and, for discrete variables, the chi-square test, were used to assess statistical significance. Kaplan-Meier curves and Cox proportionalhazard regression model were used for survival analysis. The hazard ratios (HR) with confidence intervals (CI) and $\mathrm{p}$-values are presented. $p<0.05$ was regarded as statistically significant. The PASW Statistics 18 (SPSS Inc., Chicago, Illinois, USA) statistical package was used for all statistical analyses.

\section{Results}

\section{Patient characteristics at baseline}

Totally, $\mathrm{n}=932$ patients with acute ischemic stroke or TIA were admitted to the stroke unit. Among them, $n=132$ patients with mean age $73 \pm 9$ were referred for echocardiography due to suspect onset of heart failure or due to suspect cardiac embolism, other than atrial fibrillation. $\mathrm{N}=34$ had documented atrial fibrillation and were thus excluded. Of the patients with heart dysfunction had 61 diastolic dysfunction and 16 systolic dysfunction.

Of the included patients with echocardiography, 58\% were found to have heart dysfunction. Detailed clinical characteristics of the study population are presented in Table 1.

\section{Survival data}

The mean follow-up period was $56 \pm 22$ months (min 1, $\max 92$ ). At the end of the follow-up period, 39/132 patients had died. The all-cause mortality was 35\% among patients with heart dysfunction, and $22 \%$ among patients with normal heart function (n.s.). All-cause mortality was associated with higher age $(\mathrm{p}<0.01)$, higher $\mathrm{mRS}$ at 3 -month follow-up $(\mathrm{p}<0.01)$, high CRP $(\mathrm{p}<0.05)$, 
Table 1 Characteristics of the acute ischemic stroke or TIA cohort by heart dysfunction or normal heart function

\begin{tabular}{|c|c|c|c|c|}
\hline & Total & Heart dysfunction & Normal heart function & P-values \\
\hline & $n=132$ & $n=77$ & $\mathrm{n}=55$ & \\
\hline Age $($ mean $\pm S D)$ & $73.3 \pm 9.2$ & $74.4 \pm 8.0$ & $71.7 \pm 10.6$ & 0.100 \\
\hline Male (\%) & 52.3 & 51.9 & 52.7 & 0.930 \\
\hline Stroke (\%) & 85.6 & $93.5^{* *}$ & 74.5 & 0.002 \\
\hline TIA (\%) & 14.4 & $6.5^{* *}$ & 25.5 & 0.002 \\
\hline NIHSS scores & $3.4 \pm 4.7$ & $3.9 \pm 5.1$ & $2.9 \pm 4.1$ & 0.297 \\
\hline \multicolumn{5}{|l|}{ mRS at 3-months follow-up } \\
\hline$\leq 2(\%)$ & 84.7 & $78.9^{*}$ & 92.7 & 0.030 \\
\hline$>2(\%)$ & 15.3 & $21.1^{*}$ & 7.3 & 0.030 \\
\hline All-cause mortality (\%) & 29.5 & 35.1 & 21.8 & 0.100 \\
\hline \multicolumn{5}{|l|}{ Clinical examinations } \\
\hline Systolic BP (mmHg) (mean \pm SD) & $169.0 \pm 29.5$ & $170.0 \pm 32.3$ & $167.8 \pm 25.4$ & 0.680 \\
\hline Diastolic BP (mmHg) (mean \pm SD) & $94.2 \pm 17.6$ & $95.0 \pm 19.6$ & $93.1 \pm 14.5$ & 0.548 \\
\hline Heart rate (beats/min) (mean $\pm S D)$ & $77.2 \pm 18.0$ & $77.8 \pm 18.3$ & $76.4 \pm 17.8$ & 0.660 \\
\hline \multicolumn{5}{|l|}{ Laboratory variables } \\
\hline S-Creatinine $(\mu \mathrm{mol} / \mathrm{L})($ mean $\pm \mathrm{SD})$ & $84.1 \pm 38.2$ & $86.3 \pm 43.8$ & $81.0 \pm 28.5$ & 0.444 \\
\hline $\mathrm{CRP}(\mathrm{mg} / \mathrm{L})($ mean $\pm \mathrm{SD})$ & $16.2 \pm 32.4$ & $16.7 \pm 34.3$ & $15.6 \pm 29.7$ & 0.859 \\
\hline cTNT $(\mu \mathrm{g} / \mathrm{L})($ mean $\pm \mathrm{SD})$ & $0.06 \pm 0.29$ & $0.08 \pm 0.37$ & $0.03 \pm 0.04$ & 0.417 \\
\hline \multicolumn{5}{|l|}{ Echocardiogram parameters } \\
\hline LVEF (\%) & $57.6 \pm 9.8$ & $56.0 \pm 12.0^{*}$ & $60.3 \pm 3.2$ & 0.017 \\
\hline LVDD (cm) (mean \pm SD) & $4.9 \pm 0.8$ & $4.9 \pm 0.9$ & $4.7 \pm 0.7$ & 0.438 \\
\hline Left atrium $\left(\mathrm{cm}^{2}\right)($ mean $\pm S D)$ & $19.8 \pm 4.4$ & $20.7 \pm 4.6^{* *}$ & $18.3 \pm 3.6$ & 0.004 \\
\hline Right atrium $\left(\mathrm{cm}^{2}\right)($ mean $\pm S D)$ & $16.2 \pm 3.9$ & $16.5 \pm 4.2$ & $15.7 \pm 3.4$ & 0.309 \\
\hline $\mathrm{PA}$ mmHg (mean $\pm \mathrm{SD})$ & $31.0 \pm 8.4$ & $30.8 \pm 6.9$ & $31.4 \pm 11.4$ & 0.795 \\
\hline Stroke volume (mean \pm SD) & $72.7 \pm 19.7$ & $68.8 \pm 18.5^{*}$ & $91.0 \pm 15.7$ & 0.037 \\
\hline E/A ratio $($ mean $\pm S D)$ & $0.9 \pm 0.4$ & $0.9 \pm 0.4$ & $0.9 \pm 0.3$ & 0.988 \\
\hline $\mathrm{S} / \mathrm{D}$ ratio $($ mean $\pm \mathrm{SD})$ & $1.4 \pm 0.5$ & $1.4 \pm 0.5$ & $1.1 \pm 0.1$ & 0.324 \\
\hline \multicolumn{5}{|l|}{ Cardiovascular risk factors } \\
\hline Smoking (\%) & 14.4 & 19.6 & 8.3 & 0.102 \\
\hline Hypertension (\%) & 59.1 & 59.7 & 58.2 & 0.858 \\
\hline Diabetes mellitus (\%) & 18.9 & 16.9 & 21.8 & 0.476 \\
\hline Hypercholesterolemia (\%) ${ }^{1}$ & 13.9 & 15.5 & 11.8 & 0.558 \\
\hline \multicolumn{5}{|l|}{ Cardiovascular diseases } \\
\hline Myocardial infarction (\%) & 15.9 & 19.5 & 10.9 & 0.184 \\
\hline Angina pectoris (\%) & 15.9 & 18.2 & 12.7 & 0.398 \\
\hline \multicolumn{5}{|l|}{ Comorbidity } \\
\hline Pulmonary embolism (\%) & 1.5 & 0.0 & 3.6 & 0.092 \\
\hline Previous ischaemic stroke (\%) & 17.4 & 19.5 & 14.5 & 0.461 \\
\hline eGFR <60 (mL/min) $(\%)^{2}$ & 32.3 & 38.9 & 23.1 & 0.063 \\
\hline Anaemia $(\%)^{3}$ & 11.7 & 13.2 & 9.6 & 0.541 \\
\hline
\end{tabular}


Table 1 Characteristics of the acute ischemic stroke or TIA cohort by heart dysfunction or normal heart function (Continued)

\begin{tabular}{|c|c|c|c|c|}
\hline \multicolumn{5}{|l|}{ Pre-stroke medications } \\
\hline ACE inhibitors (\%) & 19.7 & 22.1 & 16.4 & 0.416 \\
\hline Angiotensin receptor blockers (\%) & 18.2 & 14.3 & 23.6 & 0.170 \\
\hline Beta-blockers (\%) & 36.4 & 41.6 & 29.1 & 0.142 \\
\hline Diuretics (\%) & 26.5 & 28.6 & 23.6 & 0.527 \\
\hline Aspirin (\%) & 42.4 & 44.2 & 40.0 & 0.634 \\
\hline Warfarin (\%) & 0.8 & 1.3 & 0.0 & 0.396 \\
\hline Clopidogrel (\%) & 1.5 & 1.3 & 1.8 & 0.810 \\
\hline Aspirin + Dipyridamol (\%) & 1.5 & 1.3 & 1.8 & 0.810 \\
\hline Dipyridamol (\%) & 7.6 & 6.5 & 9.1 & 0.578 \\
\hline \multicolumn{5}{|l|}{ Post-stroke medications } \\
\hline ACE inhibitors (\%) & 30.5 & 34.2 & 25.5 & 0.283 \\
\hline Angiotensin receptor blockers (\%) & 23.7 & 21.1 & 27.3 & 0.408 \\
\hline Beta-blockers (\%) & 44.3 & 51.3 & 34.5 & 0.056 \\
\hline Diuretics (\%) & 32.8 & 34.2 & 30.9 & 0.691 \\
\hline Aspirin (\%) & 82.4 & 81.6 & 83.6 & 0.760 \\
\hline Warfarin (\%) & 8.4 & 7.9 & 9.1 & 0.808 \\
\hline Clopidogrel (\%) & 3.1 & 5.3 & 0.0 & 0.084 \\
\hline Aspirin + Dipyridamol (\%) & 2.3 & 3.9 & 0.0 & 0.136 \\
\hline Dipyridamol (\%) & 46.6 & 39.5 & 56.4 & 0.056 \\
\hline
\end{tabular}

NIHSS, National Institutes of Health Stroke Scale; mRS, modified rankin scale; BP, blood pressure; S-Creatinine, serum creatinine; CRP, C-reactive protein; cTNT, cardiac troponin T; LVEF, left ventricular ejection fraction; LVDD, left ventricular diastolic dimension; PA, pulmonary artery pressure; E/A ration, passive filling of the ventricle (early $[E]$ wave) and active filling with atrial systole (atrial $[A]$ wave); S/D ratio, systolic and diastolic component of pulmonary vein; eGFR, estimated glomerular filtration rate; ACE inhibitors; angiotensin-converting-enzyme inhibitors.

${ }_{1}^{1}$ Hypercholesterolemia defined as total serum-cholesterol $>6 \mathrm{mmol} / \mathrm{L}$.

${ }^{2}$ eGFR estimated by Cockcroft-Gault formula.

${ }^{3}$ Anaemia according to WHO definition, as hemoglobin $<130 \mathrm{~g} / \mathrm{L}$ (males) and hemoglobin $<120 \mathrm{~g} / \mathrm{L}$ (females).

${ }^{*}, P<0.05$ for comparison of heart dysfunction with normal heart function.

${ }^{* *}, P<0.01$ for comparison between heart dysfunction with normal heart function.

decreased LVEF $(\mathrm{p}<0.05)$, smoking $(\mathrm{p}<0.01)$, pre-stroke myocardial infarction $(\mathrm{p}<0.05)$, pre-stroke angina pectoris $(\mathrm{p}<0.05)$, eGFR $<60(\mathrm{~mL} / \mathrm{min})(\mathrm{p}<0.05)$, anaemia $(\mathrm{p}<0.05)$, pre-stroke treatment with clopidogrel $(\mathrm{p}<0.05)$ and no post-stroke treatment with aspirin $(\mathrm{p}<0.05)$ (for details see Table 2).

\section{Predictors of mortality}

In a univariate regression analysis of the whole ischemic stroke and TIA cohort $(n=132)$, the following factors were found to be significant indicators of poor survival: age, $m R S>2$ at 3-month follow-up, pre-stroke anaemia, CRP, smoking, pre-stroke myocardial infarction, and prestroke angina pectoris. Use of post-stroke aspirin was associated with better survival. However, when the variables which were significant in univariate analyses were further tested in a multivariate regression model, only age, smoking and pre-stroke myocardial infarction, were independently associated with all-cause mortality, while use of post-stroke aspirin was identified as a protective factor (Table 3). Heart dysfunction was not identified as an independent predictor of all-cause mortality.

In patients with heart dysfunction $(n=77)$, univariate regression analysis showed that age, NIHSS score, $\mathrm{mRS}>2$ at 3-month follow-up and previous myocardial infarction were all significant prognostic indicators associated with poor survival. Use of post-stroke aspirin was associated with better survival. When the significant variables from this analysis were further tested in the multivariate regression analysis (Table 4 ) only mRS $>2$ at 3-month follow-up was found to be an independent predictor of all-cause mortality; use of post-stroke aspirin was identified as protective factor.

\section{Discussion}

This study investigated the impact of impaired heart function on long-term all-cause mortality in a population with acute ischemic stroke or TIA. Our results show that heart dysfunction does not seem to be a predictor of all-cause mortality in this clinical setting. 
Table 2 Characteristics of the acute ischemic stroke or TIA cohort by survival at the end of the follow-up period

\begin{tabular}{lccc}
\hline & Non-survivors & Survivors & P-values \\
\hline $\mathrm{n}=132$ & $\mathrm{n}=39$ & $\mathrm{n}=93$ & \\
Age $($ mean \pm SD) & $77.5 \pm 6.8^{* *}$ & $71.5 \pm 9.6$ & 0.001 \\
Stroke (\%) & $97.4^{*}$ & 80.6 & 0.012 \\
TIA (\%) & $2.6^{*}$ & 19.4 & 0.012
\end{tabular}

$\mathrm{mRS}$ at 3-months follow-up

$\begin{array}{llcl}\leq 2(\%) & 69.2^{* *} & 91.3 & 0.001 \\ >2(\%) & 30.8^{* *} & 8.7 & 0.001\end{array}$

Laboratory variables

CRP (mg/L)

Echocardiogram parameters

LVEF
Cardiovascular risk factors

$28.0 \pm 48.9^{*} \quad 11.4 \pm 21.2 \quad 0.012$

Smoking (\%)

$55.0 \pm 12.3^{*}$

$58.8 \pm 8.2$

0.043

rdiovascular diseases

Myocardial infarction (\%)

Angina pectoris (\%)

Comorbidity

eGFR $<60(\mathrm{~mL} / \mathrm{min})(\%)^{1}$

Anaemia (\%) ${ }^{2}$

Pre-stroke medication

Clopidogrel (\%)

$29.6^{* *}$

9.1

0.009

$28.2^{*}$

10.8

0.012

$25.6^{*} \quad 11.8 \quad 0.048$

Post-stroke medication

Aspirin (\%)

$47.2^{*}$

26.1

0.023

$21.1^{*}$

7.8

0.033

$5.1^{*}$

0.0

0.028

\begin{tabular}{llll} 
Aspirin (\%) & $71.1^{*}$ & 87.1 & 0.029 \\
\hline
\end{tabular}

Only variables that are significant are listed in the table.

mRS, Modified rankin scale; CRP, C-reactive protein; LVEF, left ventricular ejection fraction; eGFR, estimated glomerular filtration rate.

1 eGFR estimated by Cockcroft-Gault formula.

${ }^{2}$ Anaemia according to WHO definition, as hemoglobin $<130 \mathrm{~g} / \mathrm{L}$ (males) and hemoglobin $<120 \mathrm{~g} / \mathrm{L}$ (females).

${ }^{*}, P<0.05 ;{ }^{* *}, P<0.01$ non-survivors compared with survivors.

Heart failure and ischemic stroke are not only two of the most common diseases in elderly people, but also two of the most common causes of death [1,4,19,24-26]. Some studies have suggested that a strong association would exist between heart failure and ischemic stroke [2-7]. For example, The Framingham study found heart failure to be one of the major risk factors for ischemic stroke [5]. Both $\mathrm{CHADS}_{2}$ score and $\mathrm{CHADS}_{2}$-Vasc score [27] take heart failure into account as one of the risk factors for stroke. However, these scores address heart failure patients with atrial fibrillation. Since heart failure often occurs in conjunction with atrial fibrillation, it is difficult to estimate the exact contribution of each of these factors to the risk of stroke and/or decreased survival after stroke. Moreover, heart dysfunction, cardiac remodeling and atrial fibrillation may all contribute to the risk of ischemic stroke and affect the prognosis thereafter.
Table 3 Univariate- and multivariate regression analyses of all-cause mortality in the total ischemic stroke or TIA cohort $(n=132)$

\begin{tabular}{lccc}
\hline Univariate & HR & $\mathbf{9 5 \% ~ C l}$ & P-values \\
\hline Age (years) & 4.903 & $2.15-11.19$ & $<0.000$ \\
mRS >2 at 3-months follow-up (\%) & 4.163 & $2.07-8.36$ & $<0.000$ \\
Anaemia (\%) & 2.462 & $1.13-5.39$ & 0.024 \\
CRP (mg/L) & 2.070 & $1.04-4.11$ & 0.037 \\
Smoking (\%) & 2.327 & $1.01-5.39$ & 0.049 \\
Myocardial infarction (\%) & 2.405 & $1.20-4.84$ & 0.014 \\
Angina pectoris (\%) & 2.530 & $1.23-5.22$ & 0.012 \\
Post-stroke Aspirin (\%) & 0.360 & $0.18-0.73$ & 0.005 \\
Heart dysfunction (\%) & & & n.s \\
Multivariate & HR & $\mathbf{9 5 \% ~ C l}$ & $\mathbf{P}$ \\
Age (years) & 5.401 & $1.97-14.78$ & 0.001 \\
mRS >2 at 3-months follow-up (\%) & & & n.s. \\
Anaemia (\%) & & & n.s. \\
CRP (mg/L) & & & n.s. \\
Smoking (\%) & 3.181 & $1.36-7.47$ & 0.008 \\
Myocardial infarction (\%) & 2.826 & $1.17-6.83$ & 0.021 \\
Angina pectoris (\%) & & & n.s. \\
Post-stroke Aspirin (\%) & 0.312 & $0.13-0.77$ & 0.011 \\
\hline mRS, Modified rankin scale; CRP, C-reactive protein. & &
\end{tabular}

As previously shown [8-10], the incidence of atrial fibrillation, which increases with age [11,28], is not only an independent risk factor for ischemic stroke, but also for worse outcome after ischemic stroke. In one of our previously published works, on data from the Swedish Heart Failure Registry, almost $50 \%$ of the patients with heart failure had associated atrial fibrillation [24]. Thus, it is difficult to study how heart dysfunction, beyond atrial fibrillation, affects prognosis after acute ischemic stroke or TIA.

At present, there are limited studies about impact the effect of heart dysfunction, in the absence of atrial fibrillation, on the long-term prognosis of ischemic stroke. A few previous studies suggested that neurologic deficits induced by stroke are more severe in patients with heart failure, regardless the type of heart dysfunction (systolic or diastolic) [29]. In the Northern Manhattan stroke study [7], evaluating 323 stroke patients from a mixed-ethnic region, heart failure was found to be a significant predictor of mortality.

Thus, the impact of heart dysfunction per se, in the absence of atrial fibrillation, on stroke and mortality is less clear. In the present work, we aimed to assess if heart dysfunction alone may affect the prognosis of ischemic stroke or TIA.

In some recent studies heart failure was associated with poor prognosis in ischemic stroke patients [12-16]. 
Table 4 Univariate- and multivariate regression analysis of all-cause mortality in the acute ischemic stroke or TIA cohort with heart dysfunction $(n=77)$

\begin{tabular}{lccc}
\hline Univariate & HR & $\mathbf{9 5 \%} \mathbf{C l}$ & P-values \\
\hline Age (years) & 3.759 & $1.58-8.96$ & 0.003 \\
NIHSS score & 1.123 & $1.03-1.23$ & 0.012 \\
mRS >2 at 3-months follow-up (\%) & 5.914 & $2.60-13.46$ & $<0.000$ \\
Myocardial infarction (\%) & 2.641 & $1.14-6.10$ & 0.023 \\
Post-stroke Aspirin (\%) & 0.292 & $0.12-0.69$ & 0.005 \\
Multivariate & HR & $\mathbf{9 5 \%} \mathbf{C l}$ & $\mathbf{P}$ \\
Age (years) & & & n.s. \\
NIHSS score & & & n.s. \\
mRS >2 at 3-months follow-up (\%) & 6.133 & $2.12-17.76$ & 0.001 \\
Myocardial infarction (\%) & & & n.s. \\
Post-stroke Aspirin (\%) & 0.174 & $0.06-0.54$ & 0.003 \\
\hline
\end{tabular}

mRS, Modified rankin scale; NIHSS, National Institutes of Health Stroke Scale.

It has been suggested that patients with heart failure who have an incident ischemic stroke have higher risk for midterm dependency and early mortality due to index stroke severity. Heart failure seems even to be a predictor for long-term mortality [13-16]. Underlying cardiovascular risk factors such as hypertension, valvular disease and coronary artery disease may explain worse prognosis in patients with ischemic stroke and history of heart failure. Regardless of LVEF in ischemic stroke patients, have heart failure in some studies been found to be associated with more severity, recurrence risk and early- and long-term mortality [13].

Dependency has been reported to be associated with heart failure, stroke severity and age [14] and it has recently been demonstrated that heart failure, atrial fibrillation and prestroke dementia are risk factors for death within 1 month of a stroke event [15].

In ischemic stroke patients with low LVEF $(\leq 35)$ it seems plausible that stroke severity, age and atrial fibrillation are independent predictors for 1-year mortality [16].

To achieve this purpose our study design was straightforward by excluding patients with concomitant atrial fibrillation. Our results indicate that heart dysfunction is not an independent predictor of all-cause mortality during long-term follow up in this cohort. Instead, we found that higher age, smoking, and pre-stroke myocardial infarction and none use of post-stroke aspirin [30-32] are independent predictors of mortality in patients with acute ischemic stroke or TIA, without atrial fibrillation. Lip et al. [33] found that previous stroke/TIA was a predictor of mortality and of the composite end-point of stroke together with mortality in heart failure patients without atrial fibrillation, especially during the first 30 days following initial diagnosis of heart failure. The difference between our study and the study of Lip et al. is that our follow-up time is longer. There are no data in the latter study on echocardiography parameters, so LVEF cannot be compared between the two studies.

It is worthwhile to point out that in our study only $7 \%$ of the total acute ischemic stroke or TIA cohort had LVEF $\leq 30 \%$. This might be due to the fact that patients with severe heart dysfunction often were associated atrial fibrillation and therefore were excluded. Moreover, patients with already known heart failure were not regularly referred to echocardiography during hospital stay in daily practice.

It may be hypothesized, that the lack of association between mortality and heart dysfunction/heart failure found in the present study may be explained by less severe strokes in the present population. Also many patients were chronically treated with long-term statins and antihypertensives, which may have had a beneficial effect on outcome. Another conceivable mechanism may be that non-valvular atrial fibrillation per se is a stronger risk factor for mortality and dependency than heart failure. Since heart failure patients with non-valvular atrial fibrillation were included in previous studies, but not in the present one, our inconsistent results may at least partly be explained by differences in study population.

Despite the limited sample size, our study is of potential interest since it examines the relationship between heart dysfunction without concomitant non-valvular atrial fibrillation - assessed immediately after onset of ischemic stroke or TIA - and long-term stroke prognosis. Moreover, our study is to our knowledge among the first studies to assess impact of heart dysfunction without concomitant atrial fibrillation on prognosis of patients with acute ischemic stroke or TIA.

\section{Limitations}

Our sample size was relatively small, since we excluded all patients with atrial fibrillation and all patients not examined with echocardiography during hospital stay. Moreover, a possible bias in the present study may be that patients with previously known heart failure were not regularly referred to echocardiography during hospital stay. Moreover, we did not control for atrial fibrillation or other comorbidities which might have debuted during the follow-up period and thus, may affect long-term prognosis. Finally, included patients did not have higher NIHSS points i.e. less severe strokes.

\section{Conclusion}

In conclusion, heart dysfunction, in the absence of atrial fibrillation, does not seem to predict long-term all-cause mortality in this population with acute ischemic stroke or TIA. However, due to our small sample size any conclusion must be drawn with great caution. A larger, prospective 
controlled study is warranted in order to confirm our findings.

\begin{abstract}
Abbreviations
ACE inhibitors: Angiotensin-converting-enzyme inhibitors; BP: Blood pressure; Cl: Confidence intervals; CRP: C-reactive protein; CT: Cerebral computertomography; CTNT: Cardiac troponin T; E/A ratio: Peak of early diastolic (E) and late diastolic (A) flow velocity; eGFR: Glomerular filtration rate; HR: Hazard ratios; LVDD: Left ventricular diastolic dimension; LVEF: Left ventricular ejection fraction; mRS: Modified Rankin Scale; NIHSS: National Institute of Health Stroke Scale; PA: Pulmonary artery pressure; S-creatinine: Serum creatinine; S/D ratio: Peak pulmonary venous flow velocity during ventricular systole (S), peak pulmonary venous flow velocity during ventricular diastole (D); SD: Standard deviation; TIA: Transient ischemic attack.
\end{abstract}

\section{Competing interests}

There is no relationship with the industry and no conflict of interest.

\section{Authors' contributions}

$\mathrm{AH}$ has done acquisition of echocardiography data, analysis and interpretation of the data, statistical analysis, and writing, drafting, and critical revising of the manuscript. MLXF has worked with the conception and design of the research, drafting and critical revising of the manuscript. $\mathrm{CH}$ has provided the epidemiological data and has worked with English language corrections, drafting and revising of the manuscript. LB has provided epidemiological data, and has worked with drafting and critical revision of the manuscript. BA has provided the epidemiological data, has worked with conception and design of the study, and with drafting and critical revising of the manuscript. All authors have read and approved the final manuscript.

\section{Acknowledgments}

We are grateful for receiving financial support from the Swedish Heart-Lung Foundation.

\section{Author details}

'Department of Clinical and Molecular Medicine, Institute of Medicine, Sahlgrenska Academy, University of Gothenburg, Gothenburg, Sweden. ${ }^{2}$ Department of Internal Medicine, Institute of Medicine, Sahlgrenska Academy, University of Gothenburg, Gothenburg, Sweden. ${ }^{3}$ Department of Internal Medicine, Sahlgrenska University Hospital/Sahlgrenska, Blå Stråket 5, 41345 Göteborg, Sweden.

Received: 23 January 2013 Accepted: 18 September 2013 Published: 23 September 2013

\section{References}

1. Roger VL, Go AS, Lloyd-Jones DM, Benjamin EJ, Berry JD, Borden WB, Bravata DM, Dai S, Ford ES, Fox CS, Fullerton HJ, Gillespie C, Hailpern SM, Heit JA, Howard VJ, Kissela BM, Kittner SJ, Lackland DT, Lichtman JH, Lisabeth LD, Makuc DM, Marcus GM, Marelli A, Matchar DB, Moy CS, Mozaffarian D, Mussolino ME, Nichol G, Paynter NP, Soliman EZ, et al: Executive summary: heart disease and stroke statistics-2012 update: a report from the American Heart Association. Circulation 2012, 125(1):188-197.

2. Hyman D, Morales-Vidal S, Schneck MJ: Antithrombotic therapy for stroke prevention in patients with heart failure. Curr Treat Options Cardiovasc Med 2012, 14(3):215-226.

3. Alberts VP, Bos MJ, Koudstaal PJ, Hofman A, Witteman JC, Stricker B, Breteler M: Heart failure and the risk of stroke: the Rotterdam Study. Eur J Epidemiol 2010, 25(11):807-812.

4. Hays AG, Sacco RL, Rundek T, Sciacca RR, Jin Z, Liu R, Homma S, Di Tullio MR: Left ventricular systolic dysfunction and the risk of ischemic stroke in a multiethnic population. Stroke 2006, 37(7):1715-1719.

5. Wolf PA, Kannel WB, McNamara PM: Occult impaired cardiac function, congestive HEART FAILURE, and risk of thrombotic stroke the Framingham Study. Neurology 1970, 20(4):373.

6. Witt BJ, Brown JRRD, Jacobsen SJ, Weston SA, Ballman KV, Meverden RA, Roger VL: Ischemic stroke after HEART FAILURE: a community-based study. Am Heart J 2006, 152(1):102-109.
7. Sacco RL, Shi T, Zamanillo MC, Kargman DE: Predictors of mortality and recurrence after hospitalized cerebral infarction in an urban community: the Northern Manhattan Stroke Study. Neurology 1994, 44(4):626-634.

8. Brand FN, Abbott RD, Kannel WB, Wolf PA: Characteristics and prognosis of lone atrial fibrillation: 30-year follow-up in the Framingham study. JAMA 1985, 254(24):3449-3453.

9. Kaarisalo MM, Immonen-räihä P, Salomaa V, Kaarsalo E, Salmi K, Sarti C, Sivenius J, Torppa J, Tuomilehto J: Atrial fibrillation and stroke. Mortality and causes of death after the first acute ischemic stroke. Stroke 1997, 28(2):311-315.

10. Wolf PA, Abbott RD, Kannel WB: Atrial fibrillation as an independent risk factor for stroke: the Framingham study. Stroke 1991, 22(8):983-988.

11. Go AS, Hylek EM, Phillips K, Chang Y, Henault LE, Selby JV, Singer DE: Prevalence of diagnosed atrial fibrillation in adults: national implications for rhythm management and stroke prevention: the AnTicoagulation and Risk Factors in Atrial Fibrillation (ATRIA) Study. JAMA 2001, 285(18):2370-2375.

12. Ois $A$, Gomis M, Cuadrado-Godia E, Jiménez-Conde J, Rodríguez-Campello A, Bruguera J, Molina L, Comin J, Roquer J: Heart failure in acute ischemic stroke. J Neurol 2008, 255(3):385-389.

13. Cuadrado-Godia E, Ois A, Roquer J: Heart failure in acute ischemic stroke. Curr Cardiol Rev 2010, 6(3):202-213.

14. Appelros P, Nydevik I, Vittanen M: Poor outcome after first-ever stroke: predictors for death, dependency, and recurrent stroke within the first year. Stroke 2003, 34(1):122-126.

15. Appelros P, Nydevik I, Seiger A, Terént A: Predictors of severe stroke: influence of preexisting dementia and cardiac disorders. Stroke 2002, 33(10):2357-2362.

16. Milionis $\mathrm{H}$, Faouzi M, Cordier M, D'Ambrogio-Remillard S, Eskandari A, Michel P: Characteristics and early and long-term outcome in patients with acute ischemic stroke and low ejection fraction. Int J Cardiol 2012. doi:10.1016/j.jijard.2012.11.036.

17. The World Health Organization: MONICA Project (monitoring trends and determinants in cardiovascular disease): a major international collaboration. WHO MONICA. Project Principal Investigators. J Clin Epidemiol 1988, 41(2):105-114.

18. Brott T, Adams HP Jr, Olinger CP, Marler JR, Barsan WG, Biller J, Spilker J, Holleran $R$, Eberle R, Hertzberg V: Measurements of acute cerebral infarction: a clinical examination scale. Stroke 1989, 20(7):864-870.

19. König IR, Ziegler A, Bluhmki E, Hacke W, Bath PM, Sacco RL, Diener HC, Weimar C, Virtual International Stroke Trials Archive (VISTA) Investigators: Predicting long-term outcome after acute ischemic stroke: a simple index works in patients from controlled clinical trials. Stroke 2008, 39(6):1821-1826.

20. Bonita R, Beaglehole R: Modification of Rankin Scale: recovery of motor function after stroke. Stroke 1988, 19(12):1497-1500.

21. Arnarsdottir L, Hjalmarsson C, Bokemark L, Andersson B: Comparative evaluation of treatment with low-dose aspirin plus dipyridamol versus aspirin only in patients with acute ischaemic stroke. BMC Neurol 2012, 12:67. doi:10.1186/1471-2377-12-67.

22. Dickenstein $\mathrm{K}$ : Diagnosis and assessment of the heart failure patient: the cornerstone of effective management. Eur J Heart Fail 2005, 7(3):303-308.

23. McMurray JJ, Adamopoulos S, Anker SD, Auricchio A, Böhm M, Dickstein K, Falk V, Filippatos G, Fonseca C, Gomez-Sanchez MA, Jaarsma T, Køber L, Lip GY, Maggioni AP, Parkhomenko A, Pieske BM, Popescu BA, Rønnevik PK, Rutten FH, Schwitter J, Seferovic P, Stepinska J, Trindade PT, Voors AA, Zannad F, Zeiher A, Bax JJ, Baumgartner H, Ceconi C, Dean V, Task Force for the Diagnosis and Treatment of Acute and Chronic Heart Failure 2012 of the European Society of Cardiology, ESC Committee for Practice Guidelines, et al: ESC guidelines for the diagnosis and treatment of acute and chronic heart failure 2012: The Task Force for the Diagnosis and Treatment of Acute and Chronic Heart Failure 2012 of the European Society of Cardiology. Developed in collaboration with the Heart Failure Association (HFA) of the ESC. Eur J Heart Fail 2012. doi:10.1093/eurjhf/hfs105.

24. Holmström A, Sigurjonsdottir R, Edner M, Jonsson A, Dahlström U, Fu ML: Increased comorbidities in heart failure patients $\geq 85$ years but declined from >90years: Data from the Swedish Heart Failure Registry. Int J Cardiol 2012. doi:10.1016/j.ijcard.2012.06.095.

25. Pulignano G, Del Sindaco D, Tavazzi L, Lucci D, Gorini M, Leggio F, Porcu M, Scherillo M, Opasich C, Di Lenarda A, Senni M, Maggioni AP, IN-CHF Investigators: Clinical features and outcomes of elderly outpatients with 
heart failure followed up in hospital cardiology units: data from a large nationwide cardiology database (IN-CHF Registry). Am Heart J 2002, 143(1):45-55.

26. Manzano L, Babalis D, Roughton M, Shibata M, Anker SD, Ghio S, van Veldhuisen DJ, Cohen-Solal A, Coats AJ, Poole-Wilson PP, Flather MD, SENIORS Investigators: Predictors of clinical outcomes in elderly patients with heart failure. Eur J Heart Fail 2011, 13(5):528-536.

27. Naccarelli GV, Panaccio MP, Cummins G, Tu N: CHADS2 and CHA2DS2-VASC risk factors to predict first cardiovascular hospitalization among atrial fibrillation/atrial flutter patients. Am J Cardiol 2012, 109(10):1526-1533.

28. Riley $A B$, Manning WJ: Atrial fibrillation: an epidemic in the elderly. Expert Rev Cardiovasc Ther 2011, 9(8):1081-1090.

29. Haeusler KG, Laufs U, Endres M: Chronic heart failure and ischemic stroke. Stroke 2011, 42(10):2977-2982.

30. Chen ZM, Sandercock P, Pan HC, Counsell C, Collins R, Liu LS, Xie JX, Warlow $C$, Peto R: Indications for early aspirin use in acute ischemic stroke : A combined analysis of 40000 randomized patients from the chinese acute stroke trial and the international stroke trial. On behalf of the CAST and IST collaborative groups. Stroke 2000, 31(6):1240-1249.

31. Kalra L, Perez I, Smithard DG, Sulch D: Does prior use of aspirin affect outcome in ischemic stroke? Am J Med 2000, 108(3):205-209.

32. Karlikaya G, Varlbas F, Demirkaya M, Orken C, Tireli H: Does prior aspirin use reduce stroke mortality? Neurologist 2006, 12(5):263-267.

33. Lip GY, Rasmussen LH, Skjøth F, Overvad K, Larsen TB: Stroke and mortality in patients with incident heart failure: the Diet, Cancer and Health (DCH) cohort study. BMJ Open 2012. doi:10.1136/bmjopen-2012-000975.

doi:10.1186/1471-2377-13-122

Cite this article as: Holmström et al:: Heart dysfunction in patients with acute ischemic stroke or TIA does not predict all-cause mortality at long-term follow-up. BMC Neurology 2013 13:122.

\section{Submit your next manuscript to BioMed Central and take full advantage of:}

- Convenient online submission

- Thorough peer review

- No space constraints or color figure charges

- Immediate publication on acceptance

- Inclusion in PubMed, CAS, Scopus and Google Scholar

- Research which is freely available for redistribution 